\title{
Extrusion of zeolites: Properties of catalysts with a novel aluminium phosphate sintermatrix
}

\author{
Jens Freiding, Florina-Corina Patcas, Bettina Kraushaar-Czarnetzki * \\ Institute of Chemical Process Engineering CVT, University of Karlsruhe, Kaiserstrasse 12, D-76128 Karlsruhe, Germany \\ Received 8 May 2007; received in revised form 15 June 2007; accepted 18 June 2007 \\ Available online 23 June 2007
}

\begin{abstract}
A novel type of mechanically strong zeolite extrudates is introduced, in which the zeolite crystals, here ZSM-5, are embedded in a sintermatrix of aluminium phosphate with the crystal structure of tridymite. The pore size distribution in the matrix can be tailored through both, the choice of the size of the embedded particles and their amount in the extrudates. At zeolite concentrations of $50 \%(\mathrm{w} / \mathrm{w})$ or higher, the mean pore diameter of the matrix $\left(D_{\text {pore }}\right)$ depends on the zeolite crystal size only, and amounts to $D_{\text {pore }} \approx 0.25 D_{\text {particle. }}$ Other than conventional matrices on alumina basis, the $\mathrm{AlPO}_{4}$ matrix does neither provide catalytic self-activity, nor does cause any alumination of the zeolite framework.

(C) 2007 Elsevier B.V. All rights reserved.
\end{abstract}

Keywords: Extrusion; Aluminium phosphate; Zeolites; Alumination; Macropores

\section{Introduction}

Extrusion is the most important shaping technique applied in the manufacturing of fixed-bed catalysts. Processed in pure form or with organic binders, zeolites as well as many other solid catalysts would not yield catalyst bodies of sufficient crush and attrition strength. In these cases, ceramic binders have to be added. Industrially used binders for zeolite extrudates are hydrous or hydroxidic forms of alumina or mixed silica-alumina. Upon calcination of the moist extrudates (greenbodies), interstitial and chemically bound water is removed, and aluminium hydroxides are transformed into $\gamma$ or other $\mathrm{Al}_{2} \mathrm{O}_{3}$ oxide types. The mechanical strength is mostly provided through adhesive forces and additionally by crosslinking of some terminal hydroxyl groups between neighbouring binder particles. However, the interconnected particles in the calcined extrudates are no longer denoted as binder but rather as "matrix". Using alumina or silica, the pore size distribution in the matrix depends' on the size of all particles present. Because of the small size of the binder particles, the occurrence of small mesopores with diameters of about $10 \mathrm{~nm}$ cannot be avoided. If additional macropores $(>50 \mathrm{~nm})$ are

\footnotetext{
* Corresponding author. Tel.: +49 721608 3947/4133; fax: +49721 6086118 . E-mail address: kraushaar@cvt.uka.de (B. Kraushaar-Czarnetzki).
}

installed, the mechanical stability of the extrudates strongly decreases with increasing macropore volume [1-3].

The main applications of zeolites as catalysts make use of their acidic properties. Binding with alumina or silica, however, may change the density of acid sites. Chang et al, and Shihabi et al. found that $\mathrm{Al}$ from alumina-based binders can be incorporated into the zeolite framework, thereby forming additional acid sites $[4,5]$. In the case of silica as binder, a decrease of the zeolite acidity was found using $\mathrm{H}$-gallosilicate (MFI) [6] and zeolite Y [7]. Effects like these are undesired, if an exactly defined acidity for a maximum product yield in a certain application is important.

This report is devoted to aluminium phosphates as alternative binders for the extrusion of zeolite catalysts. Aluminium phosphates exist in different atomic $\mathrm{Al} / \mathrm{P}$-ratios. In the composition $\mathrm{AlPO}_{4}$, they are isoelectronic with $\mathrm{SiO}_{2}$ and consist of alternating $\mathrm{AlO}_{4 / 2^{-}}$and $\mathrm{PO}_{4 / 2}$-tetrahedra. Six among the known, dense crystal modifications of $\mathrm{AlPO}_{4}$ are isostructural with modifications of silica; tridymite is one of these. In addition, many $\mathrm{AlPO}_{4}$ molecular sieves are known, of which some are isostructural with zeolites.

In the shaping of catalysts, however, aluminium phosphates have only been used as amorphous solids or hydrogels, so far. They exhibit acidic properties at atomic ratios $\mathrm{Al} / \mathrm{P}>1$, and even more pronounced as hydrogen phosphates with $A 1 / P<1$. With a composition $\mathrm{Al} / \mathrm{P} \approx 1$, the acid strength of terminal $\mathrm{OH}$-groups 
is said to be similar or even somewhat lower than in the case of $\gamma$ $\mathrm{Al}_{2} \mathrm{O}_{3}$ [8-10]. Aluminium phosphates as such have been applied as acidic catalysts in the dehydration of alcohols to ethers $[9,11]$ and in the isomerization of paraffins [12]. Most reports, however, refer to the use of aluminium phosphates as acidic carriers or binders of catalysts for HDN and HDS [13,14], (hydro-) cracking [15-21] and polymerization [22,23].

To the best of our knowledge, none of the aluminium phosphates investigated previously has found its way into industrial applications, be it as a catalyst, a carrier or as a binder. In particular, the phosphate binders for extrusion described so far exhibit no advantages over established alumina. They are at least as acidic as $\gamma-\mathrm{Al}_{2} \mathrm{O}_{3}$ and cannot substitute for alumina, if acidic matrix properties result in undesired side-reactions. In addition, many problems are encountered upon extrusion and work-up $[15,16]$. So far, there exist no systematic studies about the extrusion of aluminium phosphates although several papers report on aluminium phosphate catalysts being in extruded form [14-17,19], mostly in combination with alumina. In these literature reports, the extrusion itself and the characterization of textural and mechanical properties of the extrudates are mentioned marginally, only.

In our work, we evaluated several commercial aluminium phosphates. Among these, we identified an amorphous aluminium phosphate hydrate, which is highly suitable for the extrusion of zeolite catalysts. The finished extrudates exhibit a unique pore structure and show superior catalytic properties in the conversion of methanol to olefins, MTO [24]. Here, we will present a detailed report on the preparation and physico-chemical characterization of $\mathrm{AlPO}_{4}$-bound extrudates of ZSM-5. A further report on the catalytic properties is in preparation and will be published in the near future.

\section{Experimental}

\subsection{Materials}

We evaluated several aluminium phosphates with respect to their suitability as binders in the extrusion of zeolites, among which acidic hydrogen phosphates with atomic ratios $\mathrm{Al} / \mathrm{P}<1$ and almost neutral phosphates of the approximate composition $\mathrm{AlPO}_{4}$. Hydrogen phosphates are difficult to extrude. Furthermore, the dried greenbodies are hygroscopic and undergo deformations and cracking during calcination. Anhydrous $\mathrm{AlPO}_{4}$ forms, on the other hand, are well extrudable, but the final products are mechanically very weak. Their crush and attrition strengths are much too low for application in a catalytic reactor.

In this report, we focus on our work with a neutral aluminium phosphate hydrate $\left(\mathrm{AlPO}_{4}\right.$ aq., Fluka), which turned out to be the most suitable and interesting binder for extrusion. Thermal analysis indicated a mass loss of $23 \%(\mathrm{w} / \mathrm{w})$ upon calcination up to $1000^{\circ} \mathrm{C}$. The powder is X-ray-amorphous and exhibits an Al/P-ratio of 1. We denote this binder as "APH".

The characteristics of the zeolites (ZSM-5) used are summarized in Table 1 . Because the crystal size distributions were relatively broad, we also used corundum particles (Nabaltec) with narrow particle size distributions in different
Table 1

Characteristics of the zeolites used

\begin{tabular}{|c|c|c|c|c|}
\hline Sample number & Manufacturer & $\mathrm{Si} / \mathrm{Al}^{\mathrm{a}}$ & $\begin{array}{l}\text { Particle } \\
\text { diameter }(\mu \mathrm{m})\end{array}$ & Cation \\
\hline 1 & SüdChemie & 25 & $4-5$ & $\mathrm{NH}_{4}^{+}$ \\
\hline 2 & Exxon Mobile & 30 & $0.3-0.6$ & $\mathrm{TPA}^{+\mathrm{b}}$ \\
\hline 3 & Zeochem & 50 & $0.5-2.0$ & $\mathrm{Na}^{+}$ \\
\hline 4 & Zeochem & 250 & $0.5-2.0$ & $\mathrm{H}^{+}$ \\
\hline
\end{tabular}

according to data by the manufacturers.

b Alkaline-free synthesis.

mean diameters $(0.8,2,3$ and $4 \mu \mathrm{m})$ in order to study the influence of the size of the bound particles on the pore structure of the extrudates.

In the extrusion experiments, the solids were employed as such, i.e. without prior drying, calcination or ion exchange. The masses of adsorbed or bound water in the raw materials and of template in the case of zeolite sample 2 were determined in order to adjust the desired contents of zeolite and $\mathrm{AlPO}_{4}$ matrix in the final, calcined extrudates.

The solids need to be suspended in a liquid in order to obtain a viscous paste with plastic properties suitable for extrusion. We used a solution of $8.5 \%$ (w/w) hydroxyethyl cellulose ("HEC", Fluka) in water for this purpose. The dissolved HEC serves as a plasticizer.

\subsection{Formulation procedure}

The amount of liquid in the extrusion paste is the most important factor determining the flow properties. An insufficient content of liquid leads to a dry and brittle paste, which cannot be pressed through the nozzle of the extruder. On the other hand, if the liquid content is too high, the paste is wet, sticky and results in deliquescent extrudates. Here, we characterize the paste composition through the mass ratio of HEC solution to solids " $L / S$ ", wherein $S$ represents the combined masses of zeolite, binder and, if appropriate, of corundum particles.

The range of mass ratios suitable for extrusion was rather small, amounting to $\pm 5 \%$ of the optimum value of $L / S$. This ratio had to be adjusted depending on the relative amount of zeolite in the paste. The optimum mass ratios were $L / S=0.85$ for the pure aluminium phosphate without zeolite, and $L / S=0.6$ for extrudates consisting of $75 \%(\mathrm{w} / \mathrm{w})$ zeolite 2 , following a linear trend for zeolite contents in-between. Since similar results were obtained with the other zeolite samples, these ratios can be considered as a guideline. However, slight variations are possible depending on the water and template content of the zeolite employed.

Mixing of solids and HEC solution was always carried out at room temperature for $20 \mathrm{~min}$ in a rheo-kneader (Polydrive, Haake) at a constant rotor speed of $40 \mathrm{~min}^{-1}$. HEC solution was first poured into the mixing chamber of the kneader, and then the powder of thoroughly pre-mixed solids was added. After mixing, the paste was extruded through the nozzle of a piston extruder at a constant piston speed of $0.5 \mathrm{~cm} / \mathrm{min}$ to obtain cylindrical strings with a diameter of $2 \mathrm{~mm}$ and a length of 
approximately $30 \mathrm{~cm}$. After drying for $24 \mathrm{~h}$ at room temperature, they were broken into pieces of $5 \mathrm{~mm}$ length. The resulting greenbody particles were then transferred to a calciner where they were heated in air from ambient temperature to $550^{\circ} \mathrm{C}$ at a rate of $2{ }^{\circ} \mathrm{C} / \mathrm{min}$, and where they were kept at $550^{\circ} \mathrm{C}$ for $3 \mathrm{~h}$.

Extrudates comprising zeolite were exposed to at least one ion exchange procedure. Each was carried out at 55 or $80^{\circ} \mathrm{C}$, respectively, using $100 \mathrm{~mL}$ of an aqueous $\mathrm{NH}_{4} \mathrm{NO}_{3}$ solution $(2 \mathrm{~mol} / \mathrm{L})$ per $10 \mathrm{~g}$ of extrudates. To decompose the ammonium ions in the zeolite, calcination in air was performed as described above.

Whenever the composition of the extrudates is reported in this study, these values are referring to the finished, calcined extrudates on dry basis.

\subsection{Characterization}

The morphology of the cut extrudates was inspected by means of scanning electron microscopy (Gemini LEO 1530). The crystal structures of binder, zeolites and finished extrudates were analyzed by means of XRD using a Siemens D-500 diffractometer $(\mathrm{Cu} \mathrm{K \alpha}, \lambda=1.5406 \AA)$ after milling. For all other characterization methods, extruded samples were investigated in full size.

Specific surface areas were determined by means of nitrogen adsorption according to the BET method (ASAP 2010, Micromeritics).

The characterization of the pore structure, i.e. porosity and pore size distribution, was performed through mercury porosimetry (Autopore III, Micromeritics).

Temperature programmed desorption of ammonia $\left(\mathrm{NH}_{3}-\right.$ TPD) was applied in order to monitor the amount and type of acid sites (AutoChem 2910, Micromeritics). The measurements started with a purge in a flow of $\mathrm{He}(50 \mathrm{~mL} / \mathrm{min})$ while heating from ambient temperature to $500{ }^{\circ} \mathrm{C}$ (rate: $10^{\circ} \mathrm{C} / \mathrm{min}$ ) and holding this temperature for $60 \mathrm{~min}$. The samples were then cooled down in $\mathrm{He}$ at $50^{\circ} \mathrm{C}$, and the gas flow was switched to a mixture of $10 \% \mathrm{NH}_{3}$ in $\mathrm{He}(50 \mathrm{~mL} / \mathrm{min})$. After flushing with pure $\mathrm{He}$ at $50{ }^{\circ} \mathrm{C}$ for $3 \mathrm{~h}(100 \mathrm{~mL} / \mathrm{min})$, the temperature programmed desorption was started using a heating rate of $10^{\circ} \mathrm{C} / \mathrm{min}$ in a flow of $25 \mathrm{~mL} / \mathrm{min} \mathrm{He}$. The maximum temperature amounted to $550^{\circ} \mathrm{C}$. Ammonia was detected with a thermo conductivity detector. When several TPD plots are compiled together in a single figure, these are based on the same mass intake of zeolite; in Fig. 10, the plots were obtained from the same mass intake of matrix material.

Bulk crush strengths were measured according to ASTM D 4179 (Zwick).

\section{Results and discussion}

\subsection{Transformations during calcination of the greenbodies}

Generally, the calcination of extruded greenbodies has several purposes. First of all, organic species, e.g. templates in the zeolites and plasticizers, have to be combusted and removed

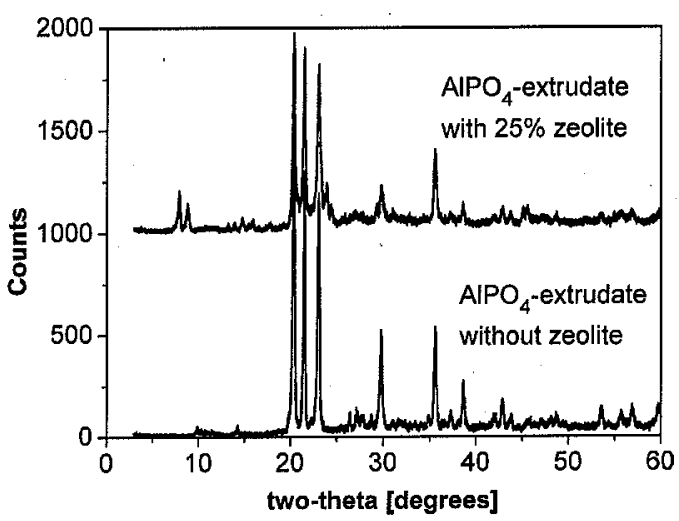

Fig. 1. XRD patterns of calcined $\mathrm{AlPO}_{4}$-extrudates with and without embedded ZSM-5.

together with residual water, be it physisorbed or chemically bound. In addition, the binder is transformed into a matrix with enhanced mechanical stability. In the case of conventional particulate binders like alumina or silica, the mechanical strength evolves through adhesive forces and cross-linking of terminal hydroxyl groups between neighbouring binder particles. Finally, the matrix is mesoporous and represents a network of more or less strongly interconnected particles with voids in-between.

Calcination has a different effect when aluminium phosphate hydrate (APH) is used as a binder. Here, a dense, continuous matrix with the crystal structure of tridymite is formed. Typical Xray diffraction patterns are shown in Fig. 1. The steps of transformation are evaporation of bound water, phase transition into $\mathrm{AlPO}_{4}$-tridymite and complete viscous sintering of the binder particles. So far, however, we could not elucidate the chronological order in which these changes occur. Due to the viscous sintering, an extensive volume reduction can be observed (Table 2). If no zeolite crystals or other foreign particles are present, the extrudates undergo shrinkage of about $33 \%$ in diameter, and a very dense, vitreous structure with high mechanical strength evolves. Extrudates consisting of pure $\mathrm{AlPO}_{4}$-tridymite may exhibit a few bubbles of enclosed air or water vapour as can be seen in the micrographs of Fig. 2. However, these bubbles provide almost no porosity and specific surface area (here: porosity $=9.7 \%$ and surface area $=0.07 \mathrm{~m}^{2} / \mathrm{g}$ ).

Table 2

Interrelation of greenbody shrinkage, pore formation and mechanical stability of $\mathrm{AlPO}_{4}$-bound extrudates of ZSM-5 (sample 2) with different zeolite contents

\begin{tabular}{|c|c|c|c|c|}
\hline $\begin{array}{l}\text { Zeolite } \\
\text { content } \\
(\%, w / w)^{a}\end{array}$ & $\begin{array}{l}\text { Shrinkage in } \\
\text { diameter upon } \\
\text { calcinations }(\%)^{\text {b }}\end{array}$ & $\begin{array}{l}\text { Porosity } \\
(\%, v / v)^{a}\end{array}$ & $\begin{array}{l}\text { Pore } \\
\text { volume } \\
\left(\mathrm{cm}^{3} / \mathrm{g}\right)^{\mathrm{a}}\end{array}$ & $\begin{array}{l}\text { Crush } \\
\text { strength } \\
(\mathrm{N})^{\mathrm{a}}\end{array}$ \\
\hline 0 & 32.7 & 9.7 & 0.05 & - \\
\hline 5 & 26.3 & 17.5 & 0.11 & - \\
\hline 10 & 18.5 & 34.7 & 0.24 & - \\
\hline 25 & 12.7 & 54.5 & 0.55 & 89 \\
\hline 50 & 9.3 & 55.1 & 0.59 & 51 \\
\hline 75 & 0 & 51.4 & 0.55 & 25 \\
\hline
\end{tabular}

${ }^{a}$ Referring to the finished extrudate without water and organics.

b Diameter of the greenbodies was $2 \mathrm{~mm}$. 


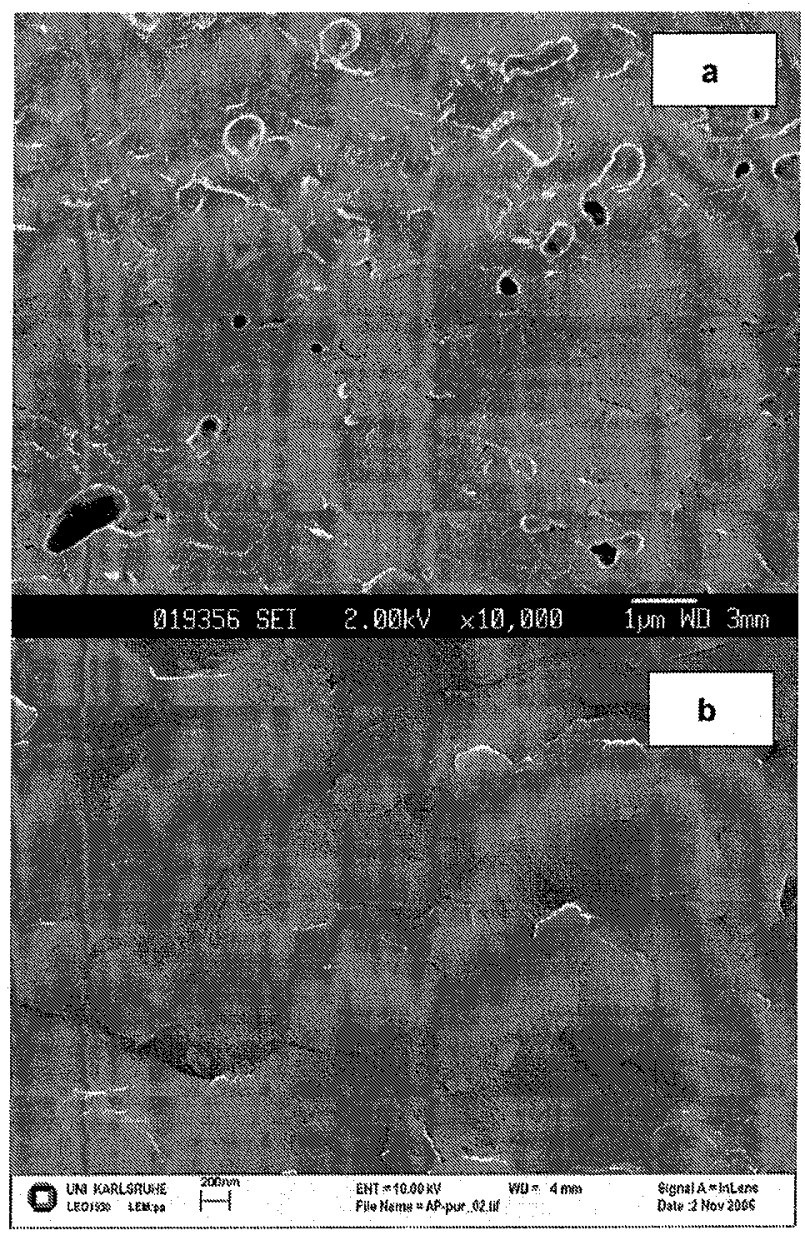

Fig. 2. SEM micrographs of cuts through extrudates of pure $\mathrm{AIPO}_{4}$-tridymite at two magnifications; bar at the bottom indicates (a) $1 \mu \mathrm{m}$ and (b) $200 \mathrm{~nm}$.

\subsection{Formation of pores in the $\mathrm{AlPO}_{4}$ matrix}

The presence of foreign, refractory particles like zeolite crystals is required in order to generate a porous structure as can be seen in the micrographs of Fig. 3 for $\mathrm{AlPO}_{4}$-bound ZSM-5 extrudates. When the concentration of such particles is low (Fig. 3a, 5\%,w/w of zeolite), the crystals are almost completely embedded in solidified sintermatrix. At portions of $10 \%(\mathrm{w} / \mathrm{w})$ or higher (Fig. $3 b$ and c), the matrix does not longer cover the zeolite crystals but rather forms distinct sinter necks inbetween.

The data in Table 2 show that an increasing content of zeolite crystals results in a reduction of the shrinkage during calcination. In parallel, porosities and pore volumes of the extrudates increase and reach maximum values at zeolite contents of about $50 \%(\mathrm{w} / \mathrm{w})$. Note that the values of porosity and pore volume were determined by means of $\mathrm{Hg}$-porosimetry. Since mercury cannot penetrate the micropores of the zeolite, these values refer to the pores in the matrix, only. Applying only $10 \%(\mathrm{w} / \mathrm{w})$ of zeolite particles nearly halves the extent of shrinking compared to extrudates of pure $\mathrm{AlPO}_{4}$, and the porosity and the pore volume are explicitly higher. At high

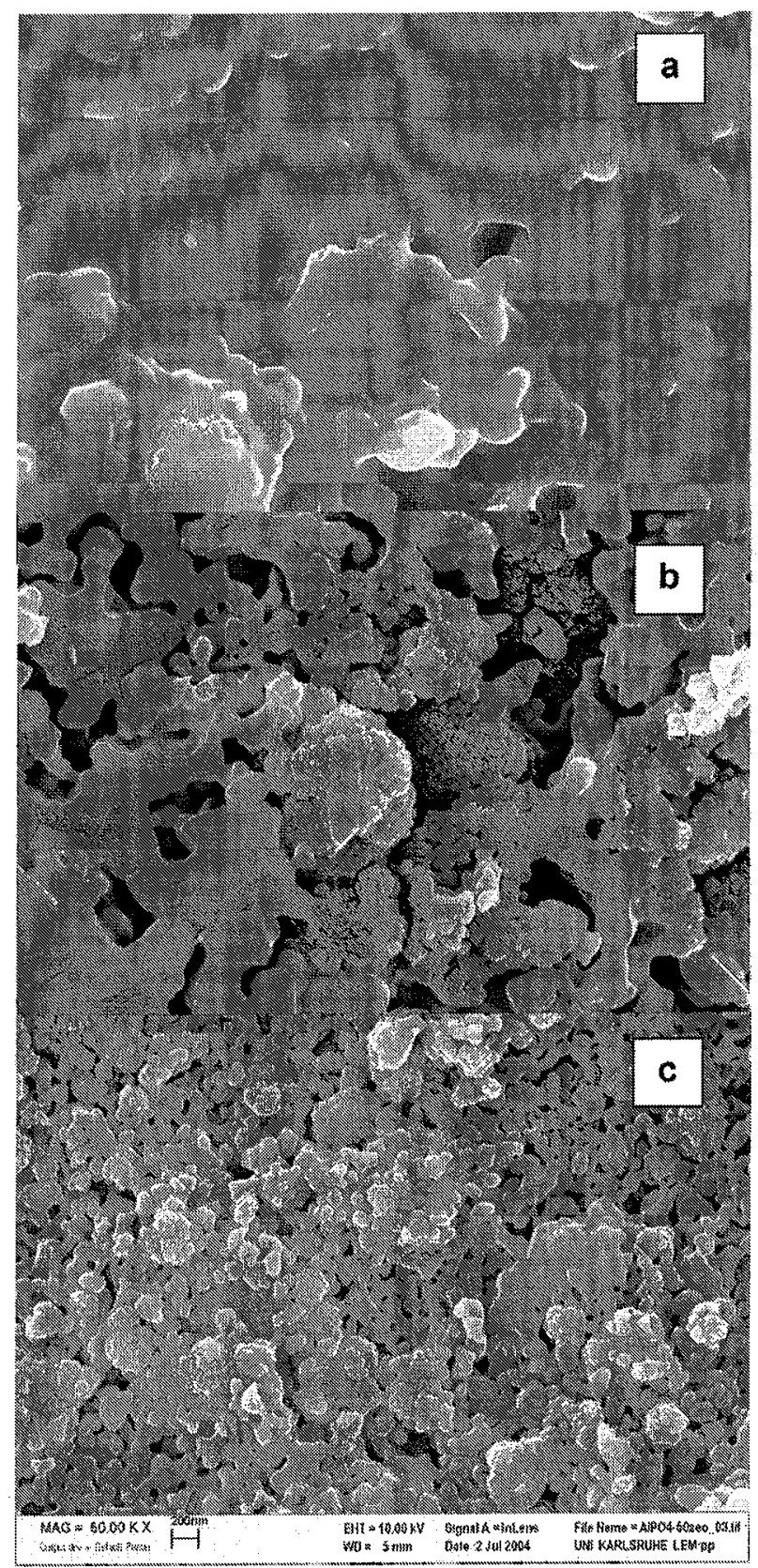

Fig. 3. SEM micrographs of $\mathrm{AlPO}_{4}$-extrudates with different ZSM-5 (sample 2) contents in $\%(w / w):(a) 5 \%$, (b) $10 \%$, and (c) $50 \%$ zeolite. The bar at the bottom indicates $200 \mathrm{~nm}$.

relative amounts of zeolite, here around $50 \%(\mathrm{w} / \mathrm{w})$, the structure is approaching a dense packing of zeolite particles. A further reduction of the matrix content has little effect, only, on the porosity and the pore volume, but it results in a reduction of the crush strengths of the extrudates.

\subsection{Designing the pore size distribution}

In extrudates with an $\mathrm{AlPO}_{4}$-sintermatrix, zeolite crystals or other refractory particles obviously act as templates for the 


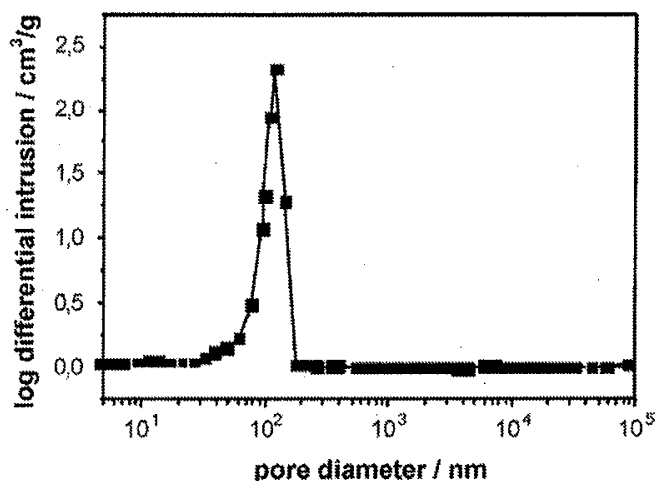

Fig. 4. Mercury intrusion plot showing the pore size distribution in an $\mathrm{AlPO}_{4}$ extrudate containing $75 \%$ (w/w) of ZSM-5 (sample 2).

sintering binder, thereby stabilising the shape of the catalyst body during calcination and determining the pore texture in the finished extrudates. For such a system it can be expected that not only the amount, but even more the size of the embedded particles should affect the pore size distribution in the finished extrudates. In Fig. 4, the mercury intrusion plot of an $\mathrm{AlPO}_{4}$ bound extrudate containing $75 \%(\mathrm{w} / \mathrm{w})$ of $\mathrm{ZSM}-5$ with a mean crystal diameter of $0.4 \mu \mathrm{m}$ (sample 2) is depicted. Apart from the micropores in the zeolite, which cannot be detected by mercury intrusion, the extrudates exhibit only macropores in the matrix with a mean width of about $100 \mathrm{~nm}$. Such a monomodal pore texture was observed in all cases.

To show more clearly a correlation between particle and pore size, we used corundum $\left(\alpha-\mathrm{Al}_{2} \mathrm{O}_{3}\right)$ particles instead of zeolite crystals because these were available in more narrow size distributions. Four different particle sizes with mean diameters of $0.8,2,3$ and $4 \mu \mathrm{m}$, each in two concentrations, i.e. 25 and $75 \%(w / w)$ corundum in the $\mathrm{AlPO}_{4}$ matrix were extruded. The corresponding results of the mercury intrusion experiments are summarized in Fig. 5. These data show that the mean pore diameters in the extrudates increase with increasing grain size of the bound particles. A more detailed analysis of these and other data indicated that the mean pore widths in the extrudates amount to about a quarter of the mean diameter of

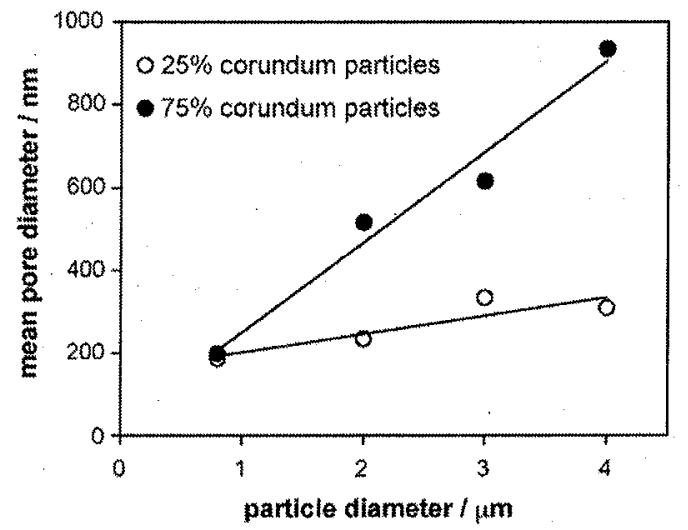

Fig. 5. Influence of the diameter and the amount of corundum particles embedded in $\mathrm{AlPO}_{4}$-tridymite on the mean pore size in the extrudates. the particles, once the content of embedded refractory particles is $50 \%(\mathrm{w} / \mathrm{w})$ or higher:

$$
\begin{aligned}
& D_{\text {pore }} \approx 0.25 D_{\text {particle }} \\
& \quad \text { (measured for } \geq 50 \%, \text { w } / \text { w of embedded particles) }
\end{aligned}
$$

At these high concentrations, the distance between the particles is very low. Theoretically, the hydraulic diameter of the channels between spheres in a dense random packing can be calculated as

$D_{\text {hydraulic }}=\frac{2}{3} \frac{\varepsilon}{1-\varepsilon} D_{\text {sphere }}$

(dense random packing of spheres).

For a typical value of the porosity $(\varepsilon)$ of $\varepsilon=0.363$, the resulting hydraulic diameters of $0.38 D_{\text {sphere }}$ are higher than the measured values of about $0.25 D_{\text {sphere }}$. This difference can be attributed to the fact that the matrix material is partially filling the cavities between the particles. Even more matrix material occupies the voids at lower particle contents (Fig. 5, 25\% of corundum). Therefore, the effect of the grain size on the pore diameter is less pronounced at particle concentrations below $50 \%(\mathrm{w} / \mathrm{w})$. However, in the case of small corundum particles $(0.8 \mu \mathrm{m})$, the mean pore sizes are almost the same, irrespective of the particle concentration.

As can be seen in Fig. 6, the grain size of the particles has no pronounced effect on the porosity of the extrudates. These data together with those of extruded zeolites (Table 2) indicate that porosities and pore volumes predominantly depend on the concentration rather than on the size of embedded particles.

In summary, it can be stated that the desired pore size in extrudates with $\mathrm{AlPO}_{4}$-sintermatrix can be adjusted by choice of the grain size of the embedded particles. An additional parameter, especially for particles exceeding $1 \mu \mathrm{m}$ in diameter, is the mass ratio of matrix to refractory particles. In contrast to conventional particulate binders, the use of APH enables to realize very large macropores in the extrudates.

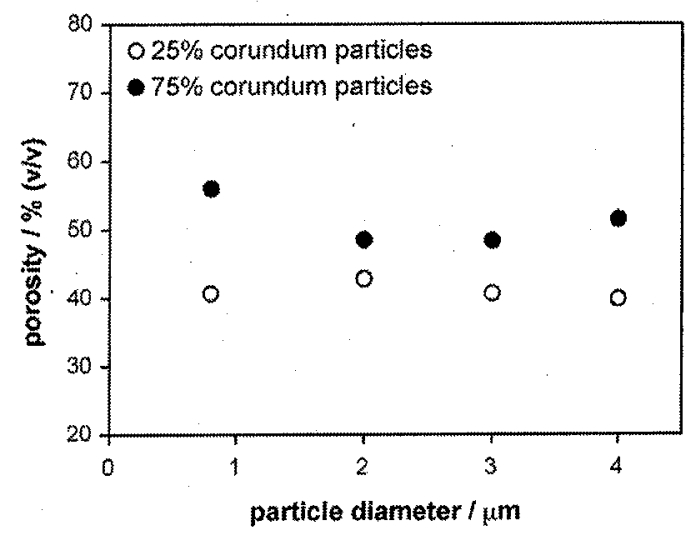

Fig. 6. Influence of the size and the amount of corundum particles embedded in $\mathrm{AlPO}_{4}$-tridymite on the porosity of the extrudates. 


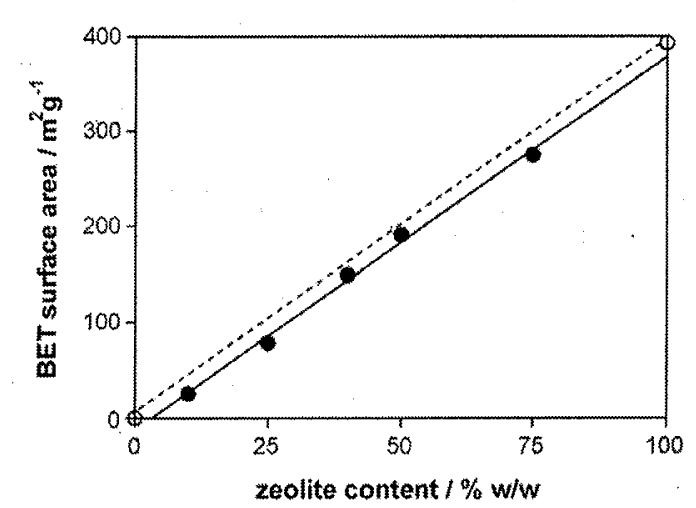

Fig. 7. Specific surface areas of $\mathrm{AlPO}_{4}$-bound extrudates as a function of the $\mathrm{H}$ ZSM-5 (sample 2) content. The hollow symbols at the margins represent pure $\mathrm{AlPO}_{4}$-tridymite (bottom left) and pure H-ZSM-5 (top right).

\subsection{Accessibility of the micropores in the zeolite}

Because the matrix in $\mathrm{AlPO}_{4}$-bound extrudates is a dense phase partially covering the surface of embedded zeolite crystals and because it cannot be excluded a priori that the material creeps into the micropores of the zeolite during sintering, the accessibility of the zeolite pores was investigated by means of nitrogen adsorption according to the BET method. Since nitrogen undergoes capillary condensation in zeolitic pores, the calculated values do not really represent BET surface areas. Nevertheless, this method is suitable to compare the adsorption capacities of pure zeolite powder with those of extruded samples because the specific surface area of the matrix is negligible as compared to that of the zeolite crystals. The surface area of pure $\mathrm{AlPO}_{4}$-extrudates is $0.07 \mathrm{~m}^{2} / \mathrm{g}$, and $\mathrm{AlPO}_{4}$-bound extrudates containing $75 \%(\mathrm{w} / \mathrm{w})$ of non-porous corundum particles $(0.8 \mu \mathrm{m}$ diameter) have a surface area of $4 \mathrm{~m}^{2} / \mathrm{g}$, only. In the case of pure ZSM-5 powder (sample 2 after calcination) the value amounts to $392 \mathrm{~m}^{2} / \mathrm{g}$. In Fig. 7, the hollow circles at the margins represent the values of pure matrix and of pure ZSM-5 powder. The connecting dotted line indicates the theoretical maximum surface areas as a function of the zeolite content. The filled data points were obtained from zeolite extrudates, and they obviously follow a linear trend that is nearly congruent with the dotted line. These results demonstrate that the micropore volume of embedded zeolite crystals is almost fully accessible. At very low zeolite contents $(\leq 5 \%)$, it is likely that the crystals are covered and plugged by the sintermatrix. This is also indicated by the SEM-photograph of the extrudate with $5 \%$ (w/w) zeolite (Fig. 3a).

It should be noticed that BET data are based on equilibrium measurements. Hence, they provide information about the adsorption capacity, but do not tell how fast the adsorption proceeds. Since all micropores in ZSM-5 are interconnected, they could, in principle, be filled completely by nitrogen even if most of the pore mouths are plugged. However, catalytic measurements indicate that pore diffusion resistances are comparable or even lower in $\mathrm{AlPO}_{4}$-bound extrudates than in conventional alumina- or silica-bound extrudates once the zeolite content exceeds 5\% (w/w) [24].

\subsection{Acidity of $\mathrm{AlPO}_{4}$-bound zeolite extrudates}

\subsubsection{General behaviour: interaction with phosphate species}

Generally, the plots of $\mathrm{NH}_{3}-\mathrm{TPD}$ measurements of $\mathrm{H}-\mathrm{ZSM}$ 5 show two peaks: a low temperature peak at $100-250^{\circ} \mathrm{C}$ and a high-temperature peak at $300-500^{\circ} \mathrm{C}$. The former stems from weakly acidic silanol groups that cover the external surface of the crystals and/or arise from lattice defects. The hightemperature peak is assigned to Brønsted acid sites, which are generated, if $\mathrm{Al}^{3+}$ replaces $\mathrm{Si}^{4+}$ in the zeolite lattice, and the resulting negative charge is compensated by a proton ( $\mathrm{H}$-form).

Samples 1,2 and 4 of the zeolites used in this study were extruded in their $\mathrm{NH}_{4}-$, TPA- or H-forms, respectively. Zeolite 2 was synthesized alkaline-free, and calcination without further ion exchange transforms the TPA- into the $\mathrm{H}$-form. $\mathrm{A} \mathrm{NH}_{3}-$ TPD plot of the calcined zeolite powder is depicted in Fig. 8. The high-temperature peak of Brønsted acid sites is well visible. The second TPD plot in Fig. 8 was taken from $\mathrm{AlPO}_{4}$ bound extrudates produced with the same zeolite (no. 2) in the original TPA-form. The calcination of the extrudates should have resulted in the decomposition of TPA ${ }^{+}$and the formation of Brønsted acid sites. However, no high-temperature peak, but rather a shoulder at the low temperature peak emerged. We ascribe this effect to an interaction of phosphate species with the Brønsted acid sites. We observed that an aqueous suspension of the APH contains a considerable amount of dissolved phosphate ions. In the course of the formulation procedure, these could migrate into the zeolite crystals. The interaction of phosphorous species with zeolite acid sites has been reported in the literature by several authors [25-30], mostly using orthophosphoric acid in order to modify zeolites systematically. There are contradictory observations about the precise nature of the interaction; a review of the proposed mechanisms is given by Caro et al. [26]. However, a decrease in acidity was always reported. Lischke et al. found that the initial acidity of zeolites can be restored by elution with hot water [25]. In case of our extrudates, this method was not successful. Rather, repeated ion exchange procedures with $\mathrm{NH}_{4} \mathrm{NO}_{3}$ solution were required to recover the acid sites. Thereby, the regeneration could not be achieved beyond a certain degree,

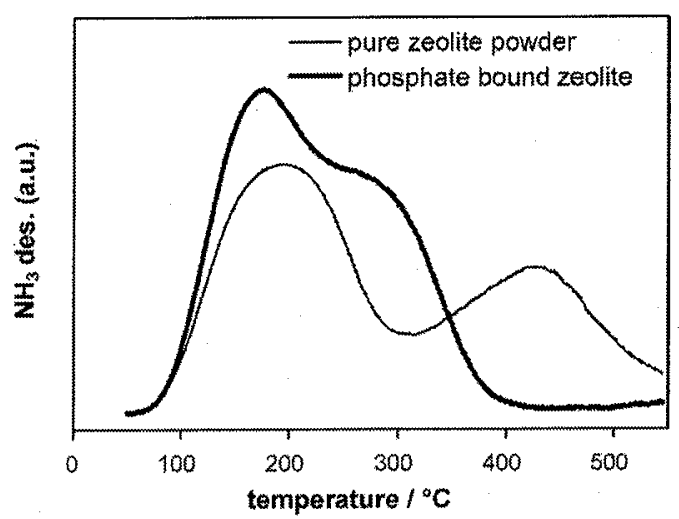

Fig. 8. $\mathrm{NH}_{3}-\mathrm{TPD}$ plots of pure H-ZSM-5 powder (zeolite 2 after calcination) and of $\mathrm{AlPO}_{4}$-bound extrudate containing zeolite 2 . 

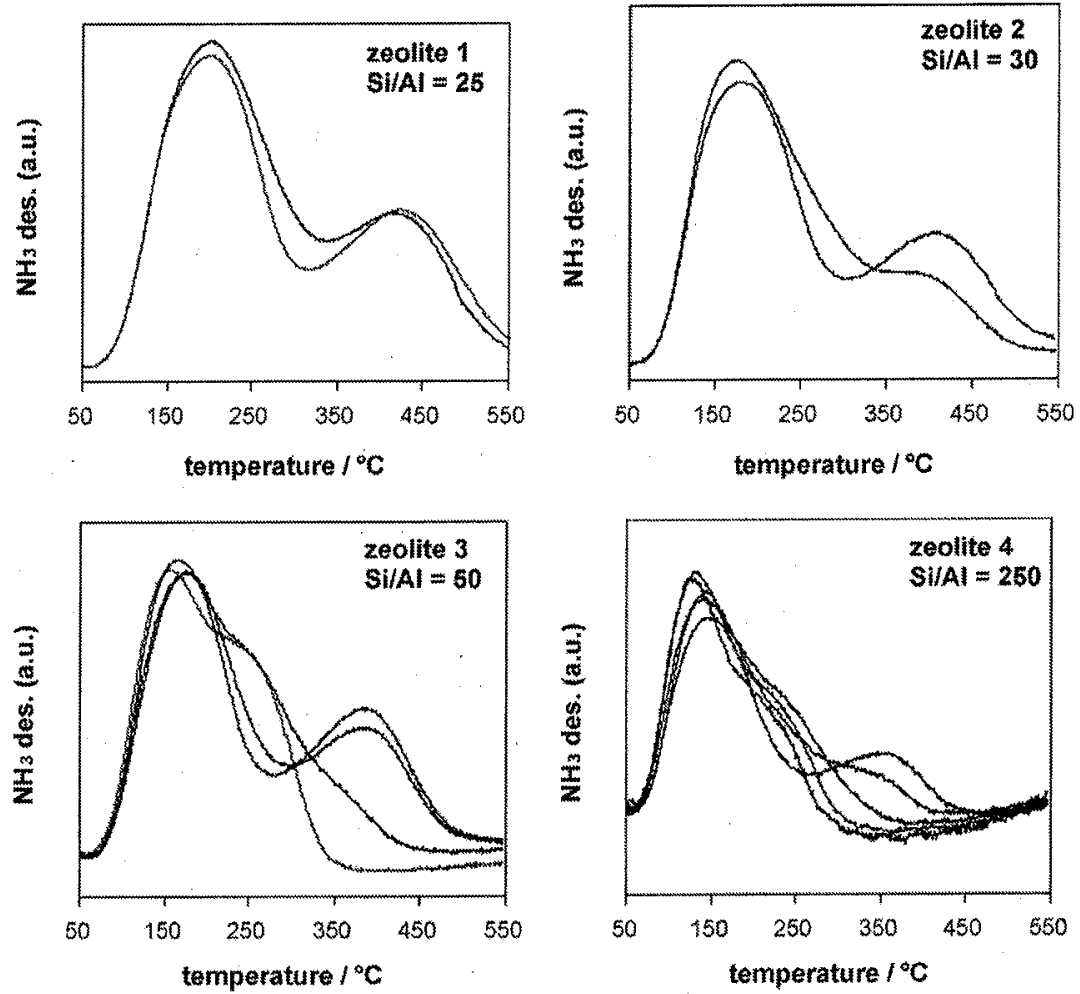

Fig. 9. Influence of the $\mathrm{Si} / \mathrm{Al}$ ratio of the zeolites in $\mathrm{AlPO}_{4}$-bound extrudates on the recovery of the high-temperature peak in $\mathrm{NH}_{3}-\mathrm{TPD}$ plots by means of repeated ion exchange-calcination steps. Temperature of the $\mathrm{NH}_{4} \mathrm{NO}_{3}$ solution for exchange of zeolites $1-3: 55^{\circ} \mathrm{C}$; of zeolite $4: 80^{\circ} \mathrm{C}$.

neither by a prolongation of the ion exchange process nor through replacing used by fresh $\mathrm{NH}_{4} \mathrm{NO}_{3}$ solution for several times. A calcination step was necessary before a subsequent ion exchange led to a further increase in the acidity. In the case of extrudates of ZSM-5 no. 2, two ion exchange-calcination sequences were required until the original zeolite acidity could be restored.

The type of counter ion in the zeolite has no effect on this general behaviour. Of course, a zeolite in the Na-form exhibits no initial Brønsted acidity, and ion exchange is necessary anyway to change $\mathrm{Na}^{+}$against protons. However, four exchange-calcination sequences were necessary to develop the full acidity of $\mathrm{AlPO}_{4}$-bound sample 3 (50\%, w/w zeolite), whereas this could be accomplished in a single exchange when alumina was used as a binder. These findings lead us to the assumption that the interaction with phosphate species is not restricted to acid sites but can also occur, if other chargecompensating cations are present.

\subsubsection{Influence of the Si/Al ratio on the interaction with phosphate species}

Our results indicate that it is neither the type of chargecompensating cation nor the zeolite crystal size, but rather the $\mathrm{Si} / \mathrm{Al}$ ratio of the zeolite which determines the effort, i.e. the number of exchange-calcination steps, required for a complete recovery of the acidity. In Fig. 9, the development to full acidity is demonstrated for the zeolite samples $1-4$, all bound in $\mathrm{AlPO}_{4}$ at a zeolite content of $50 \%(\mathrm{w} / \mathrm{w})$. Note that the $\mathrm{NH}_{3}-\mathrm{TPD}$ measurements of the ambient extrudates prior to ion exchange are not shown, but rather the plots after the first, second, etc. exchange-calcination sequence. The plots indicate that the acidity of the extrudates of samples 1 and 2 was recovered after two sequences, whereas sample 3 required four sequences. The acidity of zeolite $4(\mathrm{Si} / \mathrm{Al}=250)$ could not be restored at all at the standard temperature of the exchange solution $\left(55^{\circ} \mathrm{C}\right)$; the temperature had to be increased to $80^{\circ} \mathrm{C}$. Furthermore, five exchange-calcination sequences had to be applied. Apparently, interaction of phosphate species with Al-OM ${ }^{\mathrm{I}}-\mathrm{Si}$ groups $\left(\mathrm{M}^{\mathrm{I}}\right.$ stands for a monovalent charge-compensating cation) is the stronger, the higher the Si/Al ratio of the zeolite.

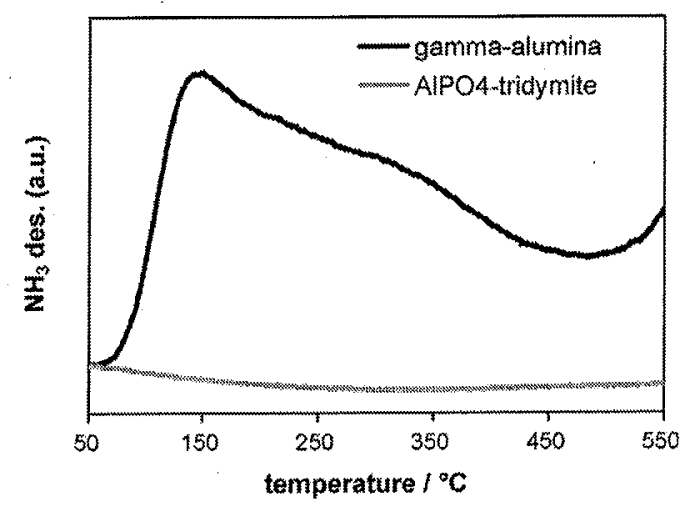

Fig. 10. $\mathrm{NH}_{3}-\mathrm{TPD}$ plots of $\mathrm{AlPO}_{4}$-tridymite and $\gamma-\mathrm{Al}_{2} \mathrm{O}_{3}$. 


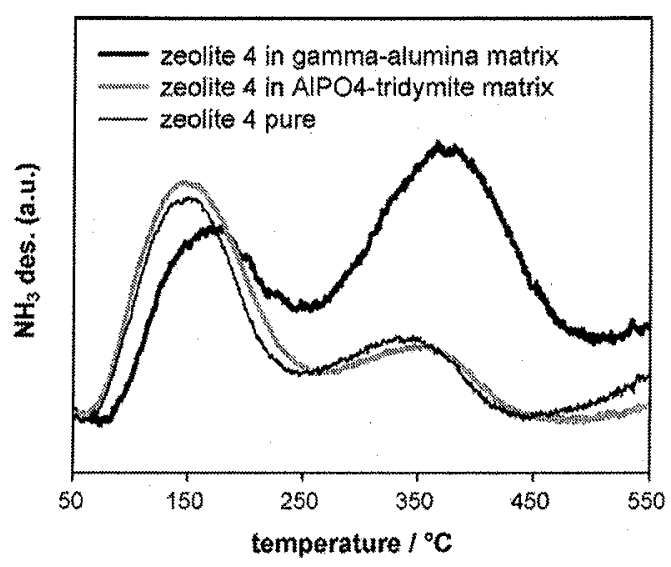

Fig. 11. $\mathrm{NH}_{3}-\mathrm{TPD}$ plots of $\mathrm{AlPO}_{4^{-}}$and $\gamma-\mathrm{Al}_{2} \mathrm{O}_{3}$-bound $\mathrm{H}-\mathrm{ZSM}-5$ (sample 4); the signals of the corresponding pure matrix materials are subtracted. For comparison: $\mathrm{NH}_{3}-\mathrm{TPD}$ plot of the pure zeolite.

\subsubsection{Acidity and alumination in comparison with $\gamma$ - $\mathrm{Al}_{2} \mathrm{O}_{3} / \mathrm{ZSM}-5$ extrudates}

In view of the catalytic properties of extruded zeolites it is important to investigate the surface acidity of the matrix itself and its impact on the acidity of the embedded zeolite. Here, we discuss these aspects and compare conventional matrices, i.e. $\gamma$ $\mathrm{Al}_{2} \mathrm{O}_{3}$ made of pseudo-boehmite binder (Pural SB 1, Sasol), with the novel tridymite sintermatrix made of APH binder. Fig. 10 shows $\mathrm{NH}_{3}-\mathrm{TPD}$ plots of the pure, powdered matrix materials. Obviously, $\gamma-\mathrm{Al}_{2} \mathrm{O}_{3}$ exhibits a much higher surface acidity than $\mathrm{AlPO}_{4}$-tridymite as related to the same mass intake. It should be kept in mind, however, that the crushed alumina matrix is mesoporous as such because it consists of agglomerates of particles with diameters of about $50 \mathrm{~nm}$. In contrast, the $\mathrm{AlPO}_{4}$-tridymite powder consists of dense particles. Many types of $\mathrm{AlPO}_{4}$ materials are known to be acidic. As mentioned in the introduction, some are used as acidic catalyst themselves. Although it cannot be excluded that $\mathrm{AlPO}_{4}$-tridymite exhibits acidic sites as well, the impact on the overall acidic behaviour will be minor because of its negligible surface area.

$\mathrm{NH}_{3}$-TPD plots of pure zeolite 4 together with those of extrudates with $\mathrm{AlPO}_{4}$ and $\gamma-\mathrm{Al}_{2} \mathrm{O}_{3}$ matrices, respectively, are depicted in Fig. 11; note that the signals of the pure matrix materials (as shown in Fig. 10) were subtracted from the plots of the zeolite extrudates in each case. Obviously, the amount of Brønsted acid sites in the zeolite was boosted after extrusion with the pseudo-boehmite binder. The incorporation of $\mathrm{Al}$ into the zeolite framework and the formation of new acid sites upon extrusion or spray drying of zeolites with various alumina-based binders have already been described by Chang et al. and Shihabi et al. [4,5]. According to these authors, the extent of $\mathrm{Al}$ incorporation is most pronounced in case of highly siliceous zeolites. In contrast, zeolites extruded with APH as a binder are not aluminated as can be deduced from the nearly congruent TPD plots of pure zeolite 4 and of the corresponding extrudate in Fig. 11.

\section{Conclusions}

We identified an amorphous aluminium phosphate hydrate (APH), which is extremely suitable as a novel binder for the extrusion of zeolite catalysts. In contrast to conventional particulate binders, APH transforms during calcination via water evaporation, viscous sintering and a phase transition into a dense, crystalline phase with the structure of tridymite. If zeolite crystals or other refractory particles are present, a pore structure evolves, formed by the embedded particles and the sinter necks of the $\mathrm{AlPO}_{4}$ matrix in-between. The pore size distribution can be tailored through choice of both, the size of the embedded particles and their relative amount in the extrudates. Other than with particulate binders, extrusion with sintering APH binder enables the realization of macropores in a narrow, monomodal size distribution.

Irrespective whether a TPA-, $\mathrm{Na}-, \mathrm{NH}_{4}$ - or $\mathrm{H}$-form of the zeolite has been employed, APH-bound extrudates of these zeolites show no acidity, probably, because phosphate species from the binder interact with the sites. However, the original acidity of the zeolite can be recovered by means of repeated ion exchange-calcination steps.

Apart from the option to realize a macropore system in the matrix, which will be beneficial to avoid pore diffusion resistances, $\mathrm{AlPO}_{4}$-bound extrudates have two other important advantages. First, the impact of a possible catalytic self-activity of the tridymite matrix can be neglected because of its diminishing small surface area. Second, the use of APH binder allows for an optimization of the $\mathrm{Si} / \mathrm{Al}$ ratio in shaped zeolite catalysts because insertion of $\mathrm{Al}$ from the binder into the zeolite framework does not occur. Both, catalytic self-activity and zeolite alumination are well-known features of alumina-based binders. For many applications in catalysis or adsorption, we anticipate that formulations of zeolite catalysts with the novel $\mathrm{AlPO}_{4}$-tridymite sinter matrices enable a better control of diffusional, acidic and mechanical properties than the use of conventional particulate matrices.

\section{References}

[1] T. Mäurer, Investigation of mass transport phenomena in the conversion of methanol to olefins over technical alumina/ZSM-5 catalysts, Ph.D. Thesis, University of Karlstuhe, Shaker Verlag GmbH, Aachen 2004.

[2] S.P. Müller, M. Kucher, C. Ohlinger, B. Kraushaar-Czarnetzki, J. Catal. 218 (2003) 419.

[3] B. Zerrer, B. Kraushaar-Czarnetzki, Ind. Eng. Chem. Res. 44 (2005) 1698.

[4] C.D. Chang, S.D. Hellring, J.N. Miale, K.D. Schmitt, J. Chem. Soc. 81 (1985) 2215.

[5] D.S. Shihabi, W.E. Garwood, P. Chu, J.N. Miale, R.M. Lago, C.T-W. Chu, C.D. Chang, J. Catal. 93 (1985) 471.

[6] P. Devadas, A.K. Kinage, V.R. Choudhary, Stud. Surf. Sci. Catal, 113 (1998) 425.

[7] X. Wu, A. Alkhawaldeh, R.G. Anthony, Stud. Surf. Sci. Catal. 143 (2002) 217.

[8] G. Marcelin, R.F. Vogel, H.E. Swift, J. Catal. 83 (1983) 42.

[9] X.-D. Peng, G.E. Parris, B.A. Toseland, P.J. Battavio, US 5,753,716 (1998).

[10] H. Itoh, A. Tada, H. Hattori, J. Catal. 76 (1982) 235.

[11] J.B. Moffat, Catal. Rev. Sci. Eng. 18 (1978) 199.

[12] R.J. Rigge, et al., US $3,879,310$ (1975). 


\section{Authors personal copy}

[13] R. Menon, H.S. Joo, J.A. Guin, Energy Fuels 10 (1996) 579-586.

[14] Y.-W. Chen, W.-C. Hsu, C.-S. Lin, B.-C. Kang, S.-T. Wu, L.-J. Leu, J.-C. Wu, Ind. Eng. Chem. Res. 29 (1990) (1830).

[15] D.A. Young, Y. Linda, US 3,354,096 (1967).

[16] L.A. Pine, US $3,904,550$ (1973).

[17] L.A. Pine, US 4,233,184 (1980).

[18] H.E. Swift, J.J. Stanulonis, E.H. Reynolds, US 4,158,621 (1979).

[19] G. Marcelin, R.F. Vogel, H.E. Swift, Ind. Eng. Chem. Prod. Res. Dev. 23 (1984) 41.

[20] D.W. Walker, A.M. Schaffer, US 4,873,211 (1989).

[21] G. Cao, L.R.M. Martens, J.L. White, T.-J. Chen, M.J. Shah, US 6,080,303 (2000).

[22] R. Glemza, US 5,030,431 (1989).
[23] T.T.P. Cheung, K.W. Willcox, M.P. McDaniel, M.M. Johnson, C. Bronnimann, J. Frye, J. Catal. 102 (1986) 10

[24] B. Kraushaar-Czarnetzki, F.-C. Patcas, EP 1700635 (2006).

[25] G. Lischke, R. Eckelt, H.-G. Jerschekewitz, B. Parlitz, E. Schreier, W. Storek, B. Zibrowius, G. Öhlmann, J. Catal. 132 (1991) 229.

[26] J. Caro, M. Bülow, M. Derewinski, J. Haber, M. Hunger, J. Kärger, H. Pfeifer, W. Storek, B. Zibrowius, J. Catal. 124 (1990) 367.

[27] H. Vinek, G. Rumplmayr, J.A. Lercher, J. Catal. 115 (1989) 291.

[28] A. Rahman, G. Lemay, A. Adnot, S. Kaliaguine, J. Catal. 112 (1988) 453.

[29] J.A. Lercher, G. Rumplmayr, Appl. Catal. 25 (1986) 215.

[30] J.C. Védrine, A. Auroux, P. Dejaifve, V. Ducarme, H. Hoser, S. Zhou, J. Catal. 73 (1981) 147. 